\title{
PENGARUH WEBSITE QUALITY TERHADAP PERCEIVED TRUST DAN DAMPAKNYA PADA REPURCHASE INTENTION PADA WEBSITE MATAHARI MALL
}

\author{
Freddy Sudiyono \\ Program Studi Magister Manajemen Universitas Tarumanagara \\ freddy_only@hotmail.com \\ Chairy \\ Program Studi Magister Manajemen Universitas Tarumanagara
}

\begin{abstract}
The purpose of this study was to determine the effect website quality to perceive trust and it's impact to repurchase intention with website brand and perceive value as the moderate variables. This is explanatory type of research, using partial least square (sem-pls) analysis technique which is measured with the help of SmartPLS 3.0 software. Data collection method is by distributing questionnaires with probablity sampling techniques taken from the unknown population of Matahari Mall website visitors, questionnaires is distribute during the time period of may to august 2017 so that been collected the number of 100 respondents who deployed in may 2017. The results of this study indicate a significant and positive direct effect of website quality and perceive trust on repurchase intention of Matahari Mall website. Perceive value also have significant impact of moderating the relation between perceive trust and repurchase intention. More over website quality has the biggest impact directly on repurchase intention. Advice that given to the Matahari Mall website is firstly to improve website quality through product content and decription evaluation and make the rules for business partner about standart of product content and description information, and also they have to improve the supervision of website content and description information.
\end{abstract}

Keywords : Website Quality, Perceive Trust, repurchase Intention, Website Brand, and Perceive Value.

\section{PENDAHULUAN}

Di era globalisasi dan perkembangan teknologi informasi yang semakin pesat ini, membawa banyak dampak positif khususnya dalam dunia pemasaran yang bergeser menjadi pemasaran moderen berbasis teknologi melalui media internet. Berdasarkan hasil survei asosiasi penyelenggara jasa internet Indonesia (APJII.com, yang diakses tanggal 15 November 2016) tercatat jumlah pengguna internet di Indonesia sampai akhir bulan oktober tahun 2016 mencapai 132,7 juta pengguna atau bisa dikatakan bahwa penetrasi internet di Indonesia sudah melampaui setengah total penduduk Indonesia yakni sebesar 51,8\%. Selain itu hasil survey juga menunjukan mayoritas perilaku pengguna internet di Indonesia sebesar 82,3 juta (62\%) digunakan untuk mengakses online shop.

Website "MATAHARI MALL" yang merupakan obyek dalam penelitian ini adalah salah satu website e-commerce di Indonesia yang dikembangkan sejak Desember 2015 oleh salah satu grup terkaya di Indonesia yaitu Lippo Group. Lippo telah menginvestasikan dana sebesar 500 juta dollar untuk website tersebut dan mengklaim telah menjadi website $E$ commerce nomor 1 di Indonesia dalam waktu setahun dari waktu peluncurannya. Meskipun telah mengklaim menjadi no.1 sebagai website E-commerce, penulis masih menemukan beberapa kekurangan diantaranya yang penulisdapatkan dari berbagai sumber pelanggan dan 
observasi. Jika dibandingkan dengan pesaing, website Matahari Mall masih tertinggal jauh dalam hal jumlah pengunjung dan total transaksi selain itu berkaitan dengan masalah teknis, sering terjadinya bug pada menu pembayaran, pembeli tidak dapat berkomunikasi dengan penjual, deskripsi produk / spesifikasi yang tidak jelas dan konfirmasi pesanan yang cukup lama. Dari beberapa hal tersebut penulis menduga bahwa terdapat kecendrungan website quality Matahari Mall masih kurang baik dan dapat mempengaruhi penurunan intensi pembelian. Menurut Chang, Kuo, Hsu, dan Cheng (2014) website quality yang diantaranya seperti system quality, service quality, dan information quality merupakan kunci utama dalam e-commerce karena persepsi konsumen terhadap kualitas dari website yang digunakan nya berdampak positif pada intensinya untuk menggunakan website tersebut dan secara langsung mempengaruhi intensi pembelian. Selain itu dalam penelitianya mereka juga membahas bahwa perceived trust positif dipengaruhi oleh website quality, dalam penelitian lebih lanjutnya menjelaskan bahwa hubungan antara perceived trust dengan website quality menjadi lebih kuat untuk konsumen yang telah mengetahui baik website brand tersebut. Trust yang dirasakan konsumen saat menggunakan website tersebut merupakan kunci yang tak kalah penting karena trust merupakan salah satu kunci penggerak konsumen untuk melakukan pembelian sehingga bisa terbentuk hubungan pembelian jangka panjang. Menurut Sam dan Tahir (2009) empathy dan trust memiliki peran yang paling signifikan untuk menggerakan seorang konsumen untuk membeli secara online dibandingkan variabel lain seperti usability, website design, information quality. Kobayashi dan Okada (2013) juga membenarkan bahwa trust sekarang ini merupakan salah satu faktor penggerak seseorang untuk melakukan pembelian online dimana trust itu sendiri dapat terbentuk dari sisi psikologis yang terbangun dari beberapa dimensi seperti store trustworthiness, perceived benelovence, perceived integrity, dan perceived competence yang kesemua dimensi trust tersebut merupakan representasi atau hasil dari website quality yang dinilai oleh konsumen. Dalam penelitian ini penulis juga ingin mengetahui perceived value yang dirasakan konsumen dari website tersebut dan seberapa jauh penggunaan brand Matahari mall yang merupakan brand extension dari departement store ternama di Indonesia yang sudah berdiri sejak 1982 yaitu Matahari. Menurut Chang dan Chen (2008) website quality dan website brand signifikan dalam mempengaruhi kepercayaan konsumen untuk menggerakan pembelian, Chang, et all (2014) mendukung hasil tersebut dimana brand sebuah website secara signifikan memperkuat hubungan antara kualitas website dan perceived trust yang artinya brand sebuah website juga memegang andil besar dalam meningkatkan kepercayaan konsumen terhadap website tersebut.

\section{HIPOPTESIS}

H1:Website Quality memiliki pengaruh yang signifikan terhadap Perceived Trust H2:Perceived Trust memiliki pengaruh yang signifikan terhadap Repurchase Intention H3:Website Quality memiliki pengaruh yang signifikan terhadap Repurchase Intention H4:Perceive Trust memediasi hubungan antara Website Quality \& Repurchase Intention H5:Brand Website memperkuat hubungan antara Website Quality \& Perceive Trust

H6:Perceived Value memperkuat hubungan antara Perceived Trust \& Repurchase Intention

Jenis penelitian ini adalah explanatory research dengan menggunakan pendekatan kuantitatif. Metode yang digunakan di dalam penelitian ini adalah survey dengan menyebarkan kuisioner kepada unit analisis yang kemudian hasilnya akan diolah menggunakan software smartPLS versi 3.0, Unit analisis yang digunakan adalah individu yang merupakan konsumen Matahari Mall yang pernah mengunjungi website Matahari Mall dan pernah melakukan pembelian setidaknya satu kali. 


\section{A. Kerangka Pemikiran}

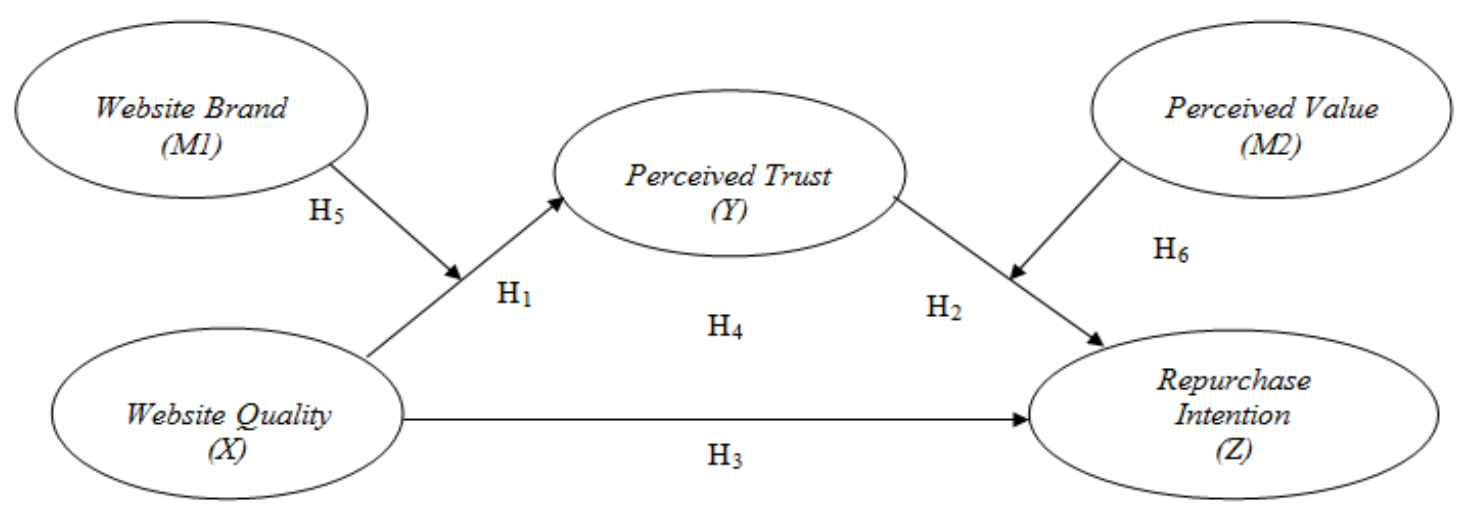

Gambar 1. Research model.

\section{B. Measurement}

Enam pertanyaan kuesioner mengenai website quality $(\mathrm{X})$ adalah "website dapat diandalkan", "website memiliki sistem yang canggih", "website dapat memahami kebutuhan pengguna", "website menyediakan layanan yang baik", "website berisi informasi produk yang akurat", "website berisi informasi produk yang berkualitas". Sedangkan enam pertanyaan kuesioner mengenai perceive trust (Y) adalah "website akan melakukan yang terbaik untuk konsumen", "website akan menyesuaikan kebutuhan konsumen", "website menjamin kualitasnya", "website dapat dikategorikan jujur", "website yang kompeten di bidangnya", "website memiliki informasi yang dapat dipercaya". Sedangkan untuk repurchase intention (Z) tiga pertanyaan kuisioner adalah "saya memiliki niat untuk melakukan pembelian ulang di website ini", "saya mungkin akan melakukan pembelian ulang di website ini ", dan "saya pasti akan melakukan pembelian ulang di website ini ". Untuk website brand (M1) empat pertanyaan kuesioner adalah "website ini lebih terkenal dibandingkan pesaing", "merek website mudah diingat dan disebut", "website terkenal dalam memberikan pelayanan dan kualitas yang baik", "webiste ini dibuat oleh perusahaan yang terpercaya". Sedangkan enam pertanyaan kuesioner untuk variabel perceived value (M2) adalah "website memberikan service yang baik", "layanan website membuat saya ingin membeli dan menggunakan produknya", "website ini mudah digunakan", "website ini efisien dan tidak membuang waktu saat digunakan", "harga produk di website ini sesuai dan masuk akal", "harga produk di website ini terjangkau". Setiap pertanyaan kuisioner diukur dengan menggunakan 5 poin penilaian dari skala Likert "1 = sangat tidak setuju" sampai "5 = sangat setuju"

\section{Sampel Penelitian}

Teknik sampling yang digunakan untuk mengambil sampel dalam penelitian ini adalah dengan menggunakan teknik purposive sampling. Dikarenakan jumlah populasi tidak diketahui, maka sampel ditentukan oleh peneliti sebanyak 100 responden. Dimana kriteria ini sudah sesuai untuk analisis menggunakan SmartPLS dengan sampel maksimal yaitu 100 .

\section{HASIL}

Penelitian ini dijalankan dengan menggunakan metode Partial Least Square (PLS) yang merupakan pendekatan permodelan kausal yang bertujuan untuk memaksimalkan variansi dari variabel laten criterion yang dapat dijelaskan oleh variabel laten predictor. 
Dalam PLS terdapat dua model evaluasi, ada evaluasi model pengukuran (Outer Model) dan evaluasi model struktural (Inner Model).

\section{A. Outer Model}

\begin{tabular}{|c|c|c|c|c|}
\hline Variabel & Indikator & Loading Factor & $A V E$ & Ketrangan \\
\hline \multirow{6}{*}{ Website Quality } & WQ_1 & 0.842 & \multirow{6}{*}{0.635} & Valid \\
\hline & WQ_2 & 0.821 & & Valid \\
\hline & WQ_3 & 0.871 & & Valid \\
\hline & WQ_4 & 0.787 & & Valid \\
\hline & WQ_5 & 0.711 & & Valid \\
\hline & WQ_6 & 0.738 & & Valid \\
\hline \multirow{6}{*}{ Perceived Trust } & PT_1 & 0.891 & \multirow{6}{*}{0.705} & Valid \\
\hline & PT_2 & 0.865 & & Valid \\
\hline & PT_3 & 0.754 & & Valid \\
\hline & PT_4 & 0.823 & & Valid \\
\hline & PT_5 & 0.874 & & Valid \\
\hline & PT_6 & 0.820 & & Valid \\
\hline \multirow{3}{*}{$\begin{array}{l}\text { Repurchase } \\
\text { Intention }\end{array}$} & PI_1 & 0.862 & \multirow{3}{*}{0.639} & Valid \\
\hline & PI_2 & 0.744 & & Valid \\
\hline & PI_3 & 0.784 & & Valid \\
\hline \multirow{4}{*}{ Website Brand } & WB_1 & 0.708 & \multirow{4}{*}{0.717} & Valid \\
\hline & WB_2 & 0.886 & & Valid \\
\hline & WB_3 & 0.892 & & Valid \\
\hline & WB_4 & 0.888 & & Valid \\
\hline \multirow{6}{*}{ Perceive Value } & PV_1 & 0.868 & \multirow{6}{*}{0.670} & Valid \\
\hline & PV_2 & 0.854 & & Valid \\
\hline & $\mathrm{PV} \_3$ & 0.785 & & Valid \\
\hline & PV_4 & 0.773 & & Valid \\
\hline & PV_5 & 0.785 & & Valid \\
\hline & PV_6 & 0.840 & & Valid \\
\hline
\end{tabular}

Tabel. 1. Convergent Validity.

Berdasarkan tabel 1 di atas, semua indikator konstruksi memenuhi kriteria nilai validitas konvergen dengan faktor loading $\geq 0,70$ dan nilai AVE pada masing-masing variabel adalah $\geq 0,50$. Sehingga dapat disimpulkan bahwa, semua data dalam diagram model adalah valid..

\begin{tabular}{|c|c|}
\hline Variabel & Composite Reliability \\
\hline WQ & 0.912 \\
\hline PT & 0.935 \\
\hline PI & 0.841 \\
\hline WB & 0.910 \\
\hline PV & 0.924 \\
\hline
\end{tabular}


Table. 2. Composite Reliability.

Berdasarkan tabel 2 di atas, semua variabel penelitian memiliki nilai reliabilitas komposit $\geq 0,70$. Hal ini menunjukkan bahwa variabel dalam penelitian ini telah memenuhi kriteria Reliability Composite untuk selanjutnya dapat dilakukan pengolahan data evaluasi Inner Model.

\section{B. Inner Model}

Dalam penelitian ini, uji Inner Model akan dilakukan dengan dua tahap pengolahan untuk mengetahui peran dua variabel moderasi di penelitian ini. Tahap pertama adalah uji tanpa variabel moderasi dengan hasil sebagai berikut:

- Without Moderate Variables

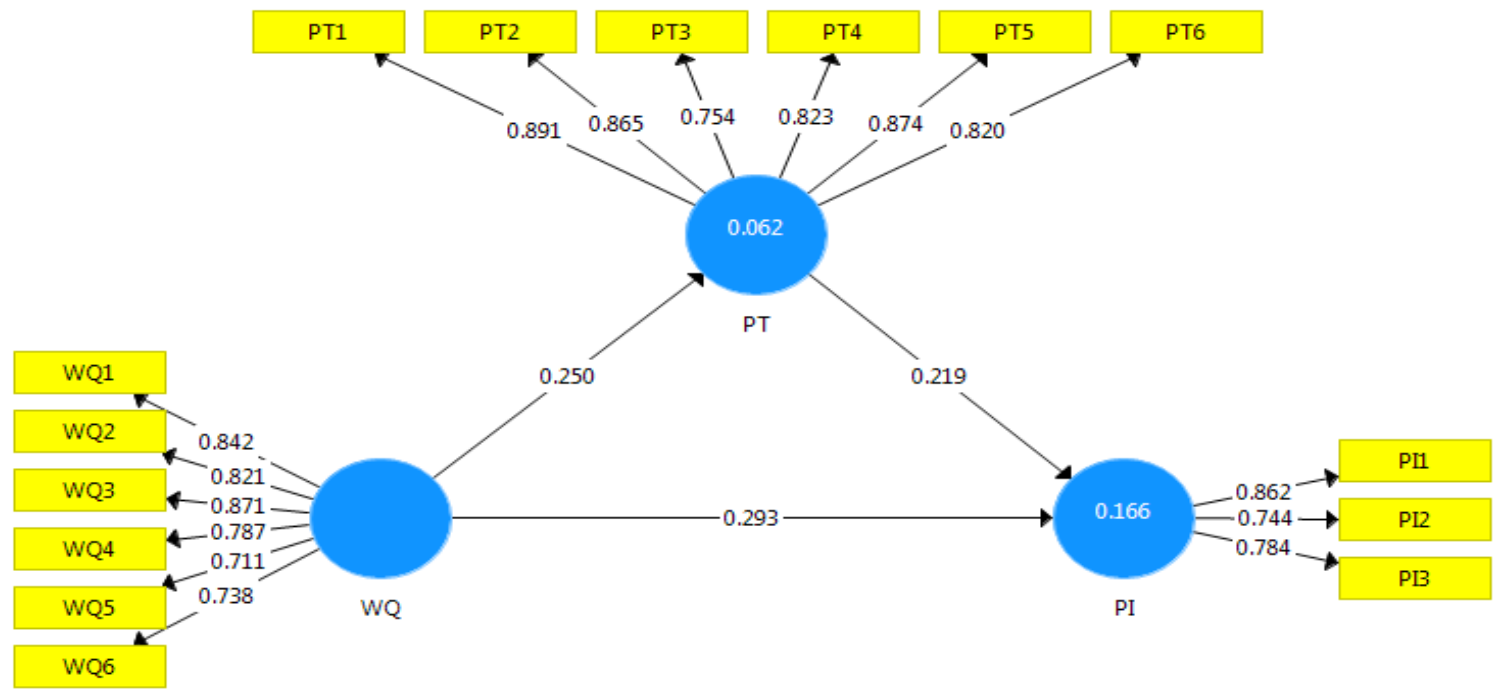

Gambar 2. PLS Algorithm tanpa variabel moderasi.

Dari Gambar 2 di atas, dapat dilihat bahwa nilai $R$ Square variabel perceived trust sebesar 0,062 (6,2\%) dipengaruhi oleh website quality sedangkan sisanya sebesar 93,8\% dipengaruhi oleh variabel lain diluar penelitian ini. $R$ Square repurchase intention sebesar $0,166(16,6 \%)$ dipengaruhi oleh perceive trust sedangkan sisanya sebesar 83,4\% dipengaruhi oleh variabel lain diluar penelitian ini. berdasarkan (Chin, 1998) nilai $R$ square sebesar 0,67 (kuat), 0,33 (moderat) dan 0,19 (lemah) sehingga dapat disimpulkan bahwa tingkat pengaruh kedua variabel tersebut tergolong lemah. 


\begin{tabular}{|c|c|c|c|}
\hline Kausalitas & Nilai Pengaruh & langsung & Tidak Langsung \\
\hline $\begin{array}{l}\text { Website } \\
\text { Quality- } \\
\text { Perceived } \\
\text { Trust }\end{array}$ & $\begin{array}{c}0.250 \times 0.250= \\
0.0625 \\
(6.25 \%)\end{array}$ & $\begin{array}{c}0.250 \\
(6.25 \%)\end{array}$ & - \\
\hline $\begin{array}{l}\text { Perceived } \\
\text { Trust- } \\
\text { purchase } \\
\text { Intention } \\
\end{array}$ & $\begin{array}{c}0.219 \times 0.292= \\
0.0639 \\
(6.39 \%)\end{array}$ & $\begin{array}{c}0.219 \\
(6.39 \%)\end{array}$ & - \\
\hline $\begin{array}{l}\text { Website } \\
\text { Quality- } \\
\text { purhcase } \\
\text { Intention }\end{array}$ & $\begin{array}{c}0.293 \times 0.347= \\
0.1016 \\
(10.16 \%)\end{array}$ & $\begin{array}{c}0.293 \\
(10.16 \%)\end{array}$ & $\begin{array}{c}0.250 \times 0.219=0.055 \\
0.0625 \times 0.0639=0.003 \\
(0.3 \%)\end{array}$ \\
\hline
\end{tabular}

Tabel. 3. Hasil Analsis Jalur.

Nilai Latent Variable Correlation dari website quality terhadap perceive trust adalah 0,250, Nilai Latent Variable Correlation dari perceive trust terhadap repurchase intetntion adalah 0,292, Nilai Latent Variable Correlation dari website quality terhadap repurchase intetntion adalah 0,347. Dari hasil pengolahan data yang telah dilakukan, untuk menghitung persentase dampaknya dapat dihitung dengan rumus (Path Coefficient X Latent Variable Correlation) X 100\%.

\begin{tabular}{|c|c|c|c|}
\hline Kausalitas & T Statistic & T Table & Signifikansi \\
\hline $\begin{array}{c}\text { Website Quality - } \\
\text { Perceived Trust }\end{array}$ & 2,785 & $>1,960$ & Signifikan \\
\hline $\begin{array}{c}\text { Perceived Trust }- \\
\text { Repurchase Intention }\end{array}$ & 2,016 & $>1,960$ & Signifikan \\
\hline $\begin{array}{c}\text { Website Quality - } \\
\text { Repurhcase Intention }\end{array}$ & 2,835 & $>1,960$ & Signifikan \\
\hline $\begin{array}{c}\text { Website Quality - } \\
\text { Perceived Trust - } \\
\text { Repurhcase Intention }\end{array}$ & 1,530 & $<1,960$ & $\begin{array}{c}\text { Tidak } \\
\text { Signifikan }\end{array}$ \\
\hline
\end{tabular}

Tabel. 4. Hasil Bootstraping Tanpa Variabel Moderasi.

Dari hasil uji analisis tahap pertama, dapat disimpulkan sebagai berikut:

- Website quality memiliki pengaruh signifikan pada perceived trust sebesar 0,250, sehingga setiap peningkatan website quality akan berdampak pada peningkatan perceive trust sebesar $0,250(6,25 \%)$.

- Perceived trust memiliki pengaruh signifikan pada repurchase intention sebesar 0,219, sehingga setiap peningkatan perceived trust akan berdampak pada repurchase Intention sebesar 0,219 (6,39\%).

- Website quality secara langsung memiliki pengaruh signifikan pada repurchase intention sebesar 0,293, sehingga setiap peningkatan website quality akan berdampak pada peningkatan repurchase intention sebesar 0,293 (10,16\%).

- Perceive trust tidak memediasi hubungan antara website quality dan repurchase intention karena tingkat pengaruhnya sangat kecil $(0,3 \%)$. 
Uji analisis tahap kedua dengan tambahan variabel moderator dengan hasil sebagai berikut:

\section{- Dengan Variabel Moderasi}

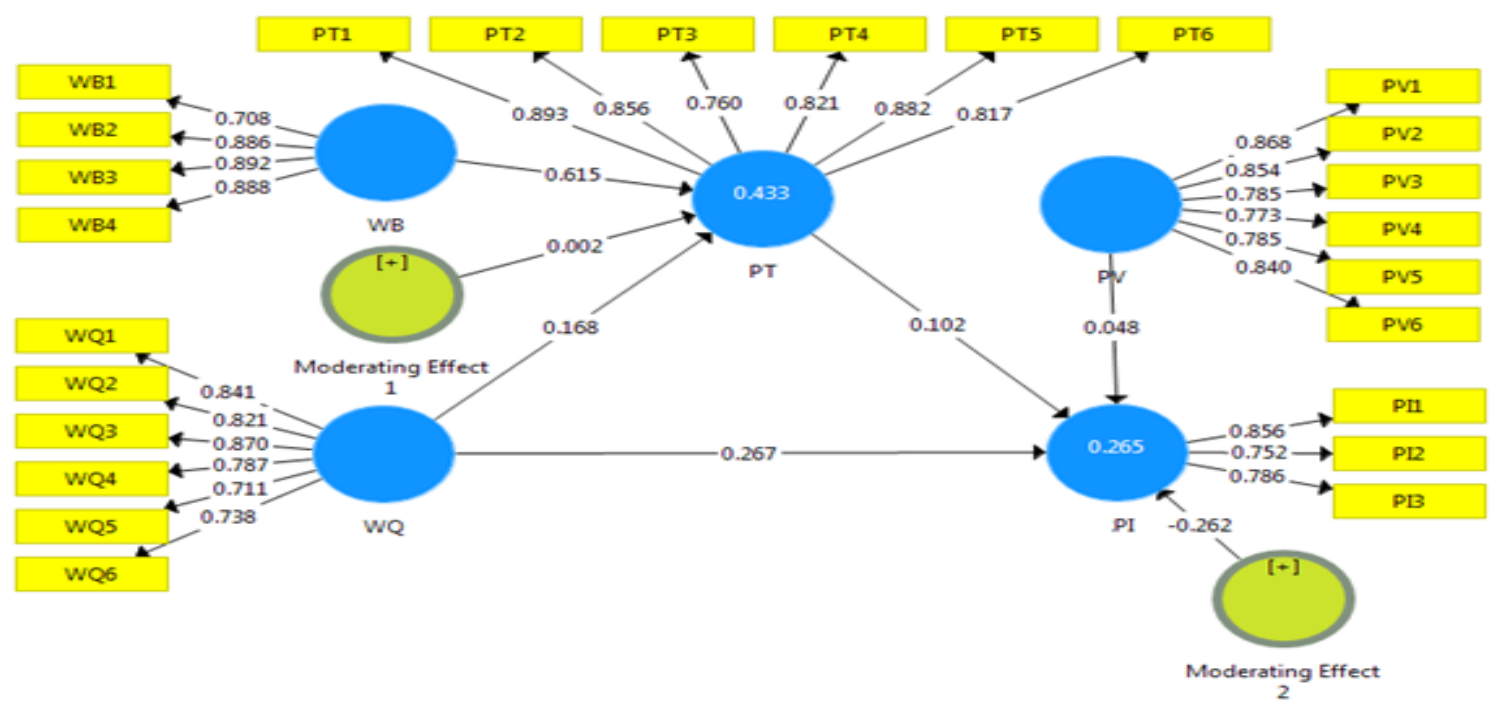

Gambar 3. PLS Algorithm Dengan Variabel Moderasi.

Dari Gambar 3 di atas, Nilai R Square tiap variabel meningkat setelah adanya peran dari variabel moderasi, perceive trust meningkat sebesar $37,1 \%$ menjadi $43,3 \%$ dengan tingkat pengaruh sedang, sedanglan repurchase intention meningkat sebesar 9,9\% menjadi $26,5 \%$ dengan tingkat pengaruh yang tetap masih lemah.

\begin{tabular}{|c|c|c|c|}
\hline Kausalitas & T Statistic & T Table & Signifikansi \\
\hline $\begin{array}{c}\text { Website Quality - } \\
\text { Perceived Trust } \\
\text { dengan moderasi } \\
\text { Website Brand }\end{array}$ & 0.032 & $<1,960$ & Tidak Signifikan \\
\hline $\begin{array}{c}\text { Perceived Trust }- \\
\text { Repurchase Intention } \\
\text { dengan moderasi } \\
\text { Perceived Value }\end{array}$ & 3.899 & $>1,960$ & Signifikan \\
\hline
\end{tabular}

Table. 5. Hasil Bootstraping Dengan Variabel Moderasi.

Dari hasil analisis tahap kedua, dapat dibentuk kesimpulan sebagai berikut:

- Website brand memperkuat pengaruh dari website quality terhadap perceive trust sebesar 37,1\%. Walaupun pengaruhnya cukup besar, namun tidak signifikan karena perceive trust sendiri tidak memediasi hubungan antara website quality dan repurchase intention, Pengaruh website quality secara langsung lebih besar dan signifikan yakni sebesar $10.16 \%$ terhadap peningkatan repurchase intention dibandingkan dengan melalui jalur perceive trust terlebih dahulu yang hanya sebesar $0.3 \%$. Sedangkan perceive value secara signifikan memperkuat hubungan antara perceive trust dan repurchase intention sebesar 9,9\%, walaupun kenaikannya tidak terlalu besar namun signifikan karena persepsi kepercayaan itu sendiri secara langsung memiliki dampak yang signifikan terhadap peningkatan repurchase intention. 


\section{KESIMPULAN}

- Website Quality memiliki pengaruh yang signifikan terhadap Perceived Trust.

- Perceived Trust memiliki pengaruh yang signifikan Terhadap Repurchase Intention.

- Website Quality memiliki pengaruh yang signifikan Terhadap Repurchase Intention secara langsung.

- Perceive Trust tidak memediasi hubungan antara Website Quality \& Repurchase Intention.

- Website Brand tidak memoderasi hubungan antara Website Quality \& Perceived Trust.

- Perceived Value memoderasi hubungan antara Perceived Trust \& Repurchase Intention.

\section{IMPLIKASI MANAJERIAL}

Berdasarkan hasil analisis dan pengelolahan data, maka implikasi Hasil Penelitian dapat diuraikan sebagai berikut:

- Website quality

Melihat dari rata-rata pernyataan variabel website quality pada nomor WQ 5 dengan bentuk pertanyaan "Website Matahari Mall memberikan informasi produk yang akurat" memiliki rata-rata skor terendah (0.711), maka perusahaan harus mengevaluasi kembali setiap keterangan deskripsi produk yang ditawarkan di website Matahari Mall dan memberikan arahan kepada partner bisnis yang berjualan melalui website Matahari Mall dengan membuat standar mengenai penjelasan informasi dan deskripsi produk yang lengkap dan efektif, pihak perusahaan juga perlu meningkatkan kinerja dari admin yang menangani mengenai content produk untuk lebih aktif menyeleksi dan mengevaluasi content produk yang kurang tepat dan menginformasikan kepada partner bisnis untuk merevisi deksripsi produk yang kurang jelas.

\section{- Perceive Trust}

Melihat dari rata-rata pernyataan variabel perceived trust pada nomor PT 3 dengan bentuk pertanyaan "website Matahari Mall merupakan website yang terjamin kualitasnnya" memiliki rata-rata skor terendah $(0,760)$, sehingga perusahaan perlu membuat berbagai program garansi yang menjamin kualitas dari service dan product yang ditawarkan, mulai dari garansi keterlambatan barang, maupun kualitas produk, selain itu pihak perusahaan juga perlu memberlakukan aturan yang jelas dan tegas kepada seluruh partner bisnis untuk menjual produk yang berkualitas sesuai dengan harga wajar pasaran, selain itu pihak perusahaan juga perlu meningkatkan kinerja daripada divisi quality control website sehingga produk yang ditawarkan selalu up to date dan berkualitas baik dari segi gambar dan deskripsi produk.

\section{- Website Brand}

Melihat dari rata-rata pernyataan variabel website brand pada nomor WB 1 dengan bentuk pertanyaan " Website Matahari Mall terkenal di bidangnya dibandingkan dengan website pesaing" memiliki rata-rata skor terendah $(0,708)$, sehingga pihak perusahaan perlu mencari cara untuk meningkatkan pamor dari pada merek website Matahari Mall dengan lebih gencar melakukan advertising yang diisi dengan penawaran promosi yang menarik di berbagai media seperti lewat billboard, iklan $\mathrm{tv}$, dan lewat media internet khususnya portal website dan aplikasi yang populer di gunakan oleh kalangan generasi Millennials mengingat mayortas konsumen yang 
gemar berbelanja online termasuk dalam golongan Millennials seperti lewat youtube ads, facebook ads, instragram dll.

\section{- Perceive Value}

Melihat dari rata-rata pernyataan variabel perceived value pada nomor PV 4 dengan bentuk pertanyaan " Desain website Matahari Mall cukup efisien sehingga tidak membuang-buang waktu saat menggunakannya" memiliki rata-rata skor terendah $(0,773)$, sehinggaa perusahaan perlu kembali melakukan riset mengenai tingkat user friendly daripada website Matahari Mall dan mempertimbangkan untuk melakukan beberapa perubahan dan penataan pada desain baik itu susunan gambar produk, kategori produk, dll, yang sesuai dengan preferensi pengguna website Matahri Mall guna mempermudah penggunaan website dalam pencarian produk.

- Berdasarkan hasil dari penelitian ini menunjukan bahwa variabel website quality merupakan variabel yang memiliki pengaruh langsung dan terbesar terhadap repurchase intention sebesar $10,16 \%$ dibandingkan perceive trust yang hanya sebesar 6,39\%, sehingga perusahaan sebaiknya lebih memfokuskan perbaikan terlebih dahulu pada variabel website quality baru kemudian dilanjutkan dengan variabel lain di penelitian ini guna memaksimalkan peningkatan repurchase intention.

\section{REFERENSI}

Hsin Hsin Chang and Su Wen Chen (2008). The Impact of online Stores environtment cues on Purchase Intention, Vol 32, No.6, 818-837.

Hwang, Y. J., \& Lee, K. C. (2012). Investigating the moderating role of uncertainly avoidance cultural values on multidimensional online trust. Information \& Management, 171-176.

I. Ghozali and H. Latan, Partial Least Squares_: Konsep, Teknik dan Aplikasi Menggunakan SmartPLS 3.0, Edisi 2. Universitas Diponegoro, 2015.

K. K. Wong, "Partial Least Squares Structural Equation Modeling ( PLSSEM) Techniques Using SmartPLS," Mark. Bull., vol. 24, 2013.

Kuo-Chien Chang, Nien-Te Kuo, Chia-Lin Hsu, and Yi-Sung Cheng (2014). The Impact of Website Quality and Perceived Trust on Customer Purchase Intention in the Hotel Sector: Website Brand and Perceived Value as Moderators, Vol. 5, No. 4, 255-260.

Mohd Fazli Mohd Sam and Md Nor Hayati Tahir (2009). Website Quality and Consumer Online Purchase Intention of Air Ticket, Vol. 09, No. 10, 4-9..

Sari, D., \& Kusuma, B. (2014). Does Luxury Brand Perception Matter In Purchase Intention? A Comparison Between A Japanese Brand and A German Brand. The Asean Marketing Journal, Vol.6, No.01, 50-59.

Sukma, A. A. (2012). Analisis Fakor-Faktoir Yang Mempengaruhi Keputusan Pembelian Melalui Social Networking Website. Jurnal Ekonomi Manajemen .

Tetsuro Kobayashi and Hitoshi Okada (2013).The effect of similliarities to previous buyers on Trust and Intention to buy from E-commerce Stores: An Expiremental Study Based on the SVS Model, 19-3 
